\title{
İnfertilitede Kullanılan Geleneksel ve Tamamlayıcı Tıp Uygulamaları
}

\section{Traditional and Complementary Medical Practices Used in Infertility}

\author{
Yasemin Soyiç $^{2}$ (iD Filiz Süzer Özkan ${ }^{1}$ (D) \\ ${ }^{1}$ Eskişehir Osmangazi Üniversitesi Sağlık Uygulama ve Araştırma Hastanesi Medikal Onkoloji Servisi, Eskişehir, TÜRKIYE \\ ${ }^{2}$ Düzce Üniversitesi Sağlık Bilimleri Fakültesi Hemşirelik Bölümü Doğum ve Kadın Hastalıkları Hemşireliği, Düzce, TÜRKIYYE
}

Geliș tarihi/ Date of receipt: 04/06/2020 Kabul tarihi/ Date of acceptance: 13/07/2020

(C) Ordu University Faculty of Health Sciences, Department of Nursing, TURKEY, Published online 30/09/2020

\section{ÖZ}

İnfertilite, Dünya Sağlık Örgütü (DSÖ) tarafından tüm dünyada milyonlarca kadını etkileyen uluslararası bir halk sağlığı sorunu olarak kabul edilmektedir. Bedensel ve psikolojik hastalıkların teşhis ve tedavisinin yanında, sağlığın devamlılığını sağlamak için farklı gelenek, inanış ve deneyimlere dayanan, açıklanabilen veya açıklanamayan uygulamaların tümü Geleneksel ve Tamamlayıcı Tıp (GETAT) olarak tanımlanmaktadır. GETAT uygulamalarının infertilitede son otuz yıldır kullanıldığı ve kanıt değeri yüksek calışmaların sayısının oldukça az olduğu bilinmektedir. Kullanılan uygulamalar ülkeler arasında kültür, coğrafya ve geleneklere göre değişkenlik göstermekle birlikte en çok kullanılanlar; akupunktur, besin takviyesi, zihin ve beden uygulamaları (hipnoz, yoga, meditasyon), homeopati ve psikoterapidir. $\mathrm{Bu}$ derlemede infertilitede kullanılan GETAT uygulamalarının tedavilerde yok sayılması veya etkinlikleri hakkında yeterli bilgi sahibi olunmaması nedeniyle, tedaviye olan etkinlikleri, yapılan çalışmalar üzerinden kısaca tartışılmıştır. Tartışmalar yöntemlerin etkinliklerini anlamak ve gelecek araştırmalara yön vermek amacı ile yapılmıştır.

Anahtar kelimeler; İnfertilite, geleneksel uygulamalar, tamamlayıcı tıp

\begin{abstract}
Infertility is recognized by the World Health Organization as an international public health problem affecting millions of women all over the world. In addition to the diagnosis and treatment of physical and psychological diseases, all of the practices that can be explained or unexplained by different traditions, beliefs and experiences to ensure the continuity of health are defined as Traditional and Complementary Medicine (TCM). It is known that TCM practices have been used in infertility for the last thirty years and the number of studies with high evidence value is very low. Although the practices used vary between countries, according to culture, geography and traditions, the most used ones are; acupuncture, nutritional supplement, mind and body practices (hypnosis, yoga, meditation), homeopathy and psychotherapy. In this review, the effects of TCM practices used in infertility are ignored in treatments or their knowledge about their effectiveness has been briefly discussed through the studies conducted. Discussions were made to understand the effectiveness of the methods and to guide future research.
\end{abstract}

Keywords: İnfertility, traditional practices, complementary medical

ORCID IDs of the authors: YS: 0000-0003-2778-1591; FSÖ: 0000-0002-2539-8591

Sorumlu yazar/Corresponding author: Dr. Öğr. Üyesi Filiz Süzer Özkan

Düzce Üniversitesi Sağlık Bilimleri Fakültesi Hemşirelik Bölümü Doğum ve Kadın Hastalıkları Hemşireliği, Düzce,

TÜRKIYE

e-posta/e-mail: filizsuzer@hotmail.com

Atıf/Citation: Soyiç Y, Özkan Süzer F. (2020). İnfertilitede kullanılan geleneksel ve tamamlayıcı tıp uygulamaları. Ordu Üniversitesi Hemşirelik Çalışmaları Dergisi, 3(2), 169-175.

DOI: $10.38108 /$ ouhcd.747957 


\section{Giriş}

İnfertilite, çiftlerin bir yıl boyunca düzenli korunmasız cinsel ilişkide bulunmalarına rağmen gebelik oluşmaması ya da gebeliği sürdürememe olarak tanımlanmaktadır (Taşkın, 2012). İnfertilite, DSÖ tarafından dünya çapında milyonlarca kadını etkileyen uluslararası bir halk sağlığı sorunu olarak kabul edilmekte ve tüm dünyada 80 milyon kadını etkilediği bildirilmektedir (Bayer ve ark., 2008). Ülkemizde infertilite oranının \%10-15 olduğu ve her altı çiftten birinin bu sorunu yaşadığı bildirilmektedir (Sezgin ve Hocaoğlu, 2014). Evli çiftlerin birçoğu daha evliliklerinin ilk yıllarını tamamlamadan çocuk sahibi olmak isteyerek hekimlere ve geleneksel yöntemlere başvurmaktadır (Kurçer ve ark., 1999). İnfertil çiftlerin önemli bir k1smı yardımcı üreme tekniklerinden, intrasitoplazmik sperm enjeksiyonunu (ICSI) veya in vitro fertilizasyon (IVF) tedavisine ihtiyaç duymaktadır. $\mathrm{Bu}$ kişilerin sadece $\% 20$ 'si canlı bebeğe sahip olabilmektedir (Avşar ve ark., 2013). Yardımcı üreme teknikleri yüksek maliyet ve zamana gereksinim duyulan tekniklerdir. Başarısız infertilite tedavisinin yüksek oranlar1, tekrarlanan IVF sikluslarından kaynaklanan stres ve artan masraflar karşısında kadınlar, başarılı bir hamilelik elde etme şanslarını arttırmak, infertiliteye bağlı streslerini azaltmak için başka tedaviler arar (Özkan ve ark., 2018).

GETAT; psikolojik ve bedensel hastalıkların teşhis ve tedavisinin yanında sağlığın devamlılığını sağlamak için farklı gelenek, inanış ve deneyimlere dayanan, açıklanabilen veya açılanamayan uygulamaların tümüdür (Sağlık Bakanlığı, 2017). GETAT uygulamalarının infertilitede son otuz yıldır kullanıldığı ve kanıt değeri yüksek calışmaların sayısının oldukça az olduğu bilinmektedir (Özkan ve ark., 2018; Özcan ve Kizilkaya Beji, 2016). Ülkemizde yapılan çalışmalarda kadınların infertilite tedavisinde GETAT kullanım oranını Edirne ve ark. (2010) \%82, Başgöl ve Beji (2016) \%78, Engin ve Pasinlioğlu (2002) \% 71, Özkan ve ark. (2018) \%51, Kurçer ve arkadaşları (1999) \%29 belirlemiştir.

Diğer ülkelerde yapılan çalışmalarda infertilite tedavisi için GETAT kullanım oranı Ürdün'de \%44 (Bardaweel ve ark., 2013), Lübnan'da \%41 (Ghazeeri ve ark., 2012), ABD'de \%91 (Clark ve ark., 2013) olarak belirlenmiştir. Kullanılan uygulamalar ülkeler arasında kültür, coğrafya ve geleneklere göre değişkenlik göstermekle birlikte infertilitede en çok kullanılanlar; akupunktur, masaj besin takviyesi, zihin ve beden uygulamaları (hipnoz, yoga, meditasyon), homeopati ve psikoterapidir. Clark ve arkadaşları'nın calışmasına göre infertilite tedavisinde doktorlarin en sik önerdikleri GETAT yöntemleri; (\%60.4) akupunktur, (\%40.9) masaj, (\%40.9) besin takviyesi, (\%47.1) dua etme, (\%46.2) psikoterapi, (\%51.6) fiziksel egzersiz ve (\%54.7) meditasyon olarak belirlenmiştir (Clark ve ark., 2013). Avustralya'da infertilite tedavisi alan kadın ve erkek hastalarla yapılan başka bir çalısmada ise kullandıkları Tamamlayıcı Alternative Tip yöntemleri; multivitaminler, bitkiler, mineral takviyeleri, doğal yöntemler, masaj ve akupunktur olarak saptanmıştır (Stankiewicz ve ark., 2007). Hemşireler; öykü alma, değerlendirme, tanılama, tanı testlerinin takibi, uygulanacak tedaviyi destekleme, çiftin eğitimi gibi infertilitenin her aşamasında etkin bir role sahiptir. Hemşirelerin GETAT yöntemleri konusunda bilgi sahibi olmas1, hasta ve yakınlarına bu yöntemler hakkında danışmanlık yapabilmeleri açısından oldukça önemlidir. GETAT yöntemlerinin yarar ve zararlarını bilen hemşireler, hastasını takip ederken olası yan etkilerin gelişip gelişmediğini de daha yakından gözleyebilir ve hastasının zarar görmesini engelleyebilir (Amanak ve ark., 2013). Bu derlemede infertilitede kullanılan GETAT uygulamalarının tedavilerde yok sayılması veya etkinlikleri hakkında yeterli bilgi sahibi olunmaması nedeniyle, tedaviye olan etkinlikleri, yapılan çalışmalar üzerinden kısaca tartışılmıştır. Tartışmalar yöntemlerin etkinliklerini anlamak ve gelecek araştırmalara yön vermek amacı ile yapılmıştır. 


\section{Geleneksel Uygulamalar}

Geleneksel uygulamalar denildiğinde kültüre özgü uygulamalar akla gelmektedir (Kurçer ve ark., 1999). Dünya'nın her yerinde çocuk sahibi olmaya verilen önem oldukça fazladır. $\mathrm{Bu}$ nedenle gebe kalmak isteyen kadınlar farklı çözümler aramaktadır. Bulunan çözümler genellikle yaşanılan toplumun kültüründen etkilenen geleneksel uygulamalardır. Geleneksel uygulamalar; dini yöntemler ya da halk hekimliği (ara ebeleri vs.) dir.

Ülkemizde yapılan çalışmalarda kadınların gebe kalmak için çok çeşitli geleneksel uygulamalara başvurdukları belirlenmiştir (Kurçer ve ark., 1999; Özkan ve ark., 2018, Başgöl ve Beji, 2016; Engin ve Pasinlioğlu, 2002). Engin ve Pasinlioğlu'nun (2002) 83 infertil kadınla yaptığı çalışmada kadınların \%80.7'sinin infertilite tanıs1 sonras1 ilk önce sağlık kuruluşuna başvurduğunu, ilerleyen zamanlarda ise hocaya/yatıra ve ara ebesine başvurma oranının $\operatorname{arttığı~görülmüştür.~}$ Çalışmadaki kadınların tamamı infertilitede kullanılan geleneksel ilaçları bildiğini, \%71'i ise geleneksel yöntem kullandığını belirtmiştir. $\mathrm{Bu}$ ilaçları uygulayanların \%66'sının sağlı̆̆ olumsuz etkilenmiştir. İnfertilitede başvurulan geleneksel uygulamaların "suyuna, buharına veya lapasina oturulanlar", "vajene yerleştirilenler" ve "yenilenler/içilenler" olmak üzere 3 gruba ayrıldığı görülmüştür. Özkan ve ark. (2018) 310 infertil kadınla yaptıkları araştırmada kadınların en çok bildikleri uygulama soğan $(\% \quad 81.9)$ ve incir $(\% 56.3)$ yemek, hocaya muska yaptırma, okuma üfleme (\%34.1) maydanozun suyuna/buharına oturma (\%30.67), kaplica ve hamama (\%30.3) gitme olarak saptanırken kadınların en çok kullandıkları uygulamaların soğan (\%65.1), incir (\%45.2), kuyruk yağ 1 (\%42.9) ve ceviz (\%41.7) olduğu saptanmıştır.

Ülkemizde yapılan diğer çalışmada Kurçer ve ark. (1999) kadınların \%36'sının otlardan vajinal ovul, \% 15'inin otu kaynatıp buğuya oturma yöntemi kullandığını saptarken Başgöl ve Beji'nin (2016) 127 infertil kadınla yaptıkları araştırmada; dua etme (\%100), gülme $(\% 98)$, komşuya gitme $(\% 91.9)$ ve namaz k1lmanın (\%79.8) en çok tercih edilen uygulamalar olduğu görülmektedir.

\section{Akupunktur}

Akupunktur, Türk Dil Kurumuna göre altın iğneler batırılarak yapılan tedavidir (TDK 2018). Merkezi sinir sistemi, hipotalamus hipofiz-overian aks ve pelvik organlar arasındaki bağlantı üzerine etki etmektedir. $\beta$ endorfin seviyesinde artış sağlar. $\beta$ endorfin seviyesindeki bu değişiklik GnRH salınımı ve menstruel siklusu etkiler. Akupunktur ayrıca gonodtropların ve over hormonlarının seviyeleri hem ovulatuar hem de anovulatuar dönemde etkileyebilmektedir. Over stimülasyonunda ovulasyonu etkileyebilmektedir (Avcıbay ve Beji, 2013). Dieterle ve arkadaşlarının (2009) yaptığ 1 şiddetli oligoastenozoospermili 57 infeltil hasta üzerine olan çalışmada; 28 hastaya çin tıbbı prensibine göre akupuntur tedavisi uygulanmış, bunun yanında 29 hastaya da plasebo akupunturu verilmiştir. Tedavi sonrası sperm konsantrasyonu ve semen hacmi karşılaştırıldığında, akupuntur tedavisi alan grupta semen hacmi ve sperm konsantrasyonunda önemli değişiklikler görülmüştür. $\mathrm{Bu}$ çalışmada gebelik oranları karşılaştırılmamıştır. Akupunkturun IVF ve ICSI üzerine etkisinin belirlenmesi için yapılan başka bir çalışmada ise; 225 infertil kadın 2 gruba alınmıştır. 1. grupta 116 kadın geleneksel çin tıbbı prensibine göre luteal faz akupunturu almıştır. 2. Grup ise plasebo akupunturu almıștır. 1. Grupta gebelik oranı $\% 33.6$ ve devam eden gebelik oran $1 \% 28.4,2$. Grupta gebelik oran 1 ise $\% 15.6$ ve devam eden gebelik oranı \%13.8 olarak görülmüştür. Sonuçlardan görüldüğü üzere luteal faz akupunkturunun IVF/ICSI tedavisinde olumlu etkisi olduğu görülmüştür (Dieterli ve ark., 2006).

Ülkemizde yapılan çalışmalarda infertilite tedavisi alan kadınların akapunktur, psikoterapi, fiziksel egzersiz gibi GETAT uygulamalarını neredeyse hiç bilmediği ve uygulanmadığı, İrlanda, Amerika gibi batı ülkelerinde yapılan çalıșmalarda ise infertilite tedavisinde akapunktur, egzersiz, bitkisel ilaç, 
psikoterapi gibi GEAT uygulamalarının daha çok kullanıldığı görülmektedir. Weiss ve ark. (2011) ABD'de Akupunkturun in vitro fertilizasyon tedavisinde en sik kullanılan GETAT yöntemi olduğunu saptamıştır. Türkiye'de bu yöntemlerin daha az biliniyor/uygulanıyor olması GETAT uygulamaları ile ilgili kanıta dayalı çalışmaların çok sınırlı olması ve hekimlerin biyomedikal yöntemlerin yanında GETAT yöntemlerini kullanımını desteklememesi nedeniyle olabilir. Ülkemizde hekimlerin infertilite tedavisinde GETAT uygulamaların önermesi/kullanma sıklığı ile ilgili bir veri bulunmamaktadır (Özkan ve ark., 2018). Ancak Clark ve ark. (2013) çalışmasında infertilite tedavisinde doktorlarin \% 60.4'ünün akupunktur, \%40.9'unun masaj, \%40.9'unun besin takviyesi, \% 47.1'inin dua etme, \%46.2'sinin psikoterapi, \%51.6'sinin fiziksel egzersiz ve \%54.7'sinin ise meditasyon önerdiği görülmektedir.

\section{Zihin Beden Uygulamaları (Hipnoz- Yoga-Meditasyon-Psikoterapi-Gevşeme Yöntemleri)}

İnsan sağllğ 1 duygusal, ruhsal ve sosyal faktörlerden doğrudan etkilenir. Zihin beden uygulamaları; gevşeme yöntemleri, hipnoz, yoga, meditasyon, bilişsel davranışcı terapiler, kapalı grup destekleri ve hayal kurma stratejileridir. Bilinçli farkındalığın infertilite üzerindeki etkinliğinin değerlendirildiği bir çalışmada 55 infertil kadın bilinçli etkinlik programını tamamlamış ve 37 kadın kontrol grubuna alınmıştır. Bilinçli farkındalık programı sonucu infertilite ile başa çıkmak için farkındalık becerilerinde, öz yetkinlikde anlamlı iyileşme sağlanmış, kontrol grubunda ise anlamlı değişme görülmemiştir. Sonuç olarak; infertilite yaşayan kadınlarda bilinçli etkinlik programının anlamlı etkinliği olduğu görülmüştür (Galhardo et al., 2013). Domar ve ark (2011), IVF tedavisiyle beraber zihinbeden terapisi uygulanan kadınlarda gebelik oranlarını daha yüksek bulmuştur. Sadece IVF tedavisi uygulanan kadınlarda gebelik oranı \%20 iken, IVF tedavisi ile birlikte zihin/ beden terapisi ile alan grupta bu oran $\% 43$ olarak saptanmıştır. Embriyo transferi sırasında uygulanan hipnozun gebelik ve implantasyon oranına etkisine bakılan bir çalışmada, hipnoterapi uygulanan hastalarda gebelik ve implantasyon oranlarının daha yüksek olduğu görülmüştür (Levitas ve ark., 2006). Yapılan çalışmalarda yoganın, infertil kadınların stres seviyesini azalttığ1 bulunmuştur (Kirca ve Pasinlioğlu, 2019, Jasani ve ark., 2016, Valoriani ve ark. 2014, Oron ve ark. 2015).

\section{Homeopati}

Homeopati Dr. Samuel Hahnemann tarafından geliştirilen ve bedenin kendi gücünü kullanarak iyileșme sağlayabileceğine inanan bir alternatif yöntemdir (Yıldız ve Ürper, 2013). "Benzer benzeri tedavi eder" ilkesinden yola çıkar. Homeopati prensibine göre bir madde aldığımızda etki ortaya çıkarır, aynı maddeyi az miktarda aldığımızda ortaya çıkardığ1 etkiyi -hastalığı- iyileştirebilir. Asıl amaç yaşam enerjisini tedavi ederek iyileşme sağlamaktır. $\mathrm{Bu}$ durum günümüz tıbbi ile açılanamaz. Homeopatinin etkinliğini kabul eden ve reddeden pek çok yayın bulunmaktadır (Avcıbay ve Beji, 2013; Özcan ve Beji, 2016, Sezer 2015). Homeopati ile yapılan innfertilite çalışmaları literatürde çok sınırlıdır. Bergman ve arkadaşlarının (2000) 67 infertil kadında Agnus castus içeren homeopatik preparat olan Phyto Hypophyson L'nin etkinliğini araştırdığ çalışmada; 37 oligomenoreli, 30 amenoreli kadına 3 ay $3 \mathrm{kez}$ ve 3 döngüde 50 damla Phyto-Hypophyson L veya plasebo verilmiştir. 67 kadının 38'inde spontan adet kanamas1, luteal fazda progesteron artışı, siklusun kısalması, erken ovulasyon ve gebelik sonucuna ulaşılmıştır. Phyto-Hypophyson L alan grupta plasebo grubuna göre daha anlamlı etki görülmüştür. Sonuç olarak çalışmada; oligomenore ve amenoreli kadınlarda PhytoHypophyson L 3-6 aylık süre boyunca kullanılabilir sonucu çıkmıştır.

\section{Biyolojik Temelli Uygulamalar (Besin Takviyesi) \\ Doğal maddelerin bulunduğu vitamin, mineral ve yiyecekler üzerinden temellenir. Kebapçılar ve arkadaşları (2013) en az bir}


doğum yapmış, primer over yetmezliği olan kadınlarda D vitamini, çinko ve bakır kan düzeyini değerlendirdiği çalışmada; primer over yetmezliği olan kadınlarda serum bakır ve çinko oranı anlamlı olarak yüksek bulunmuş, ancak sağliklı kontrol grubu ile karşılaştırıldığında vitamin $\mathrm{D}$ ve çinko kan düzeyleri anlamlı olarak daha düşük bulunmuştur. Aynı şekilde Nalavade ve arkadaşları (2016) infertil kadınların fertil kadınlara oranla besinler ile daha az demir, çinko, folik asit, kalori ve protein aldığını saptamıştır.

Ülkemizde yapılan çalışmalarda Sis ve Kırca (2018) infertil kadınların çoğunun (\%65'i) bitkisel kaynaklı bir karışım yediğini veya suyunu içtiğini (bitkisel karışımları hazırlarken çoğunlukla aslanpençesi otu, kırk kilit otu, 1sırgan otu, soğan suyu, arı sütü, propolis, keçiboynuzu pekmezi) saptarken, kadınların \%37,9'u en çok içtiği bitkisel karışımın soğan suyu kürü olduğunu belirtmiştir. Özkan ve arkadaşları (2018) infertil kadınların en çok kullandıkları uygulamaların soğan (\%65.1), incir (\%45.2), kuyruk yağ1 (\%42.9) ve ceviz (\%41.7) olduğunu saptamıştır.

$\mathrm{Bu}$ alanda yapılan çalışmalar dünyada ve Türkiye'de yetersizdir, etkinliğinin kanıtlanabilmesi için daha fazla çalışma yapılmas1 gereklidir.

\section{Sonuç}

Değişen ve gelişen dünyada doğurganlık yaşının artması, yaşam koşullarının değișmesi, sağlıksız yaşam koşulları/beslenme ile infertilite oranları her geçen gün artmakta ve en önemli sorunlardan biri haline gelmektedir. Yardımcı üreme teknikleri ise; maliyetli, uzun zaman alıcı ve kontrolün neredeyse tamamen sağllk personelinin elinde olduğu uygulamalardır. Alternatif/tamamlayıcı yöntemler ise yeterli çalışma ve kanıtla desteklenirse gelecekte infertil çiftlere deneyimleyebilecekleri yeni umut 1şıkları olacak ve tedavinin etkinliğinin artmasını sağlayacaktır.
Araştırmanın Etik Yönü/ Ethics Committee Approval: Literatür incelemesi yapılmış ve atıf yapılan literatür kaynaklar bölümünde gösterilmiştir.

Hakem/Peer-review: Dış hakem değerlendirmesi.

Yazar Katkısı/Author Contributions: Fikir/ kavram:YS, FSÖ; Tasarım: YS, FSÖ; Veri toplama ve/veya Veri İşleme: YS, FSÖ; Analiz ve/veya Yorum; YS, FSÖ; Kaynak tarama: YS, FSÖ.; Makalenin yazımı: YS, FSÖ; Eleștirel İnceleme: YS, FSÖ

Çıkar çatıșması/Conflict of interest: Çalıșmada herhangi bir çıkar çatışması yoktur.

Finansal Destek/Financial Disclosure: $\mathrm{Bu}$ çalışma herhangi bir kurum ya da kuruluş tarafından desteklenmemiştir.

\section{Calısma Literatüre Ne Kattı?}

- Dünyada infertilite oranları her geçen gün artmakta ve en önemli sorunlardan biri haline gelmektedir. GETAT uygulamaları son otuz yıldır infertilitede kullanılmakta fakat uygulamalar ülkelere göre değişkenlik göstermektedir.

- İnfertilitede kullanılan GETAT uygulamalarının tedavilerde yok sayılması veya etkinlikleri hakkında yeterli bilgi sahibi olunmaması nedeniyle, tedaviye olan etkinlikleri, yapılan çalışmalar üzerinden tartışılmıştır.

- Yöntemlerin etkinliklerini anlamayı ve gelecek araştırmalara yön vermeyi kolaylaştıracaktır.

- İnfertilite bakımında yer alan sağlık çalışanlarının GETAT uygulamaları konusunda farkındalığının artırılması sağlanacaktır.

\section{Kaynaklar}

Amanak K, Karaöz B, Sevil Ü. (2013). Alternatif/Tamamlayıcı Tıp ve Kadın Sağlığı. Derleme. TAF Preventive Medicine Bulletin, 12(4):441-448.

Avcıbay B, Beji KN. (2013). İnfertilite tedavisinde tamamlayıc1/alternatif tıp uygulamaları, Androloji Bülteni. 15(52), 71-74.

Avşar AFY, Taş EE, Akçay GY. (2013). B-12 vitamini ve infertilite, Ankara Medical Journal, 13(2), 82-88.

Bardaweel SK, Shehadeh M, Suaifan G, Kilani MV. (2013). Complementary and alternative medicineutilization by a sample of infertile couples in Jordan for infertility treatment: clinics-basedsurvey. BMC Complementary and Alternative Medicine, 13,35. 
Başgöl Ş, Beji Kızılkaya N. (2016). Use of Complementary and Alternative Medical Therapies by Women Undergoing Reproductive Technology. Turkiye Klinikleri ObstetricWomen's Health and Diseases Nursing-Special Topics, 2(3), 70-76.

Bayer SR, Alper MM, Penzias AS. (2008). Boston IVF İnfertilite El Kitabı. (2.Baskı) (Çev. Işık Ahmet Zeki, Vicdan Kubilay) İstanbul: Nobel Tip Kitapevi, s.56.

Bergman, J, Luft B, Boehmann S, Runnebaum B,Gerhard I. (2000). The Efficacy of The Complex Medication Phyto Hypophyson L In Female, Hormone-Related Sterility. A Randomized, Placebo-Controlled Clinical Double-Blind Study. Forsch Komplementarmed Klass Naturheilkd.7(4), 190-199.

Clark NA, Will MA, Moravek MB, Xu X, Fisseha S. (2013). Physician and patient use of and attitudes toward complementary and alternative medicine in the treatment of infertility. International Journal of Gynecology and Obstetric, 122, 253-257.

Dieterli S, Ying G,Hatzmann W, Neuer A. (2006). Effect of acupuncture on the outcome of in vitro fertilization and intracytoplasmic sperm injection: a randomized, prospective, controlled clinical study, Fertility and Sterility, 85(5), 1347-1351.

Dieterle S, Li C, Greb R, Barstzch F,Hatzmann W, Huang D, (2009). A prospective randomized placebo-controlled study of the effect of acupuncture in infertile patients with severe oligoasthenozoospermia, Fertility and Sterility; 92(4), 1340-1343.

Domar DA, Rrooney KL, Wiegand B, Orav JE, Alper MM, Berger BM, et al. (2011). Impact of a group mind/body intervention on pregnancy rates in IVF patients. Fertility and Sterility, 95(7), 2269-2273.

Edirne T, Gunher Arica, S, Gucuk S, Yildizhan R, Kolusari A, Adali E, Can M. (2010). Use of complementary and alternative medicines by a sample of Turkish women for infertility enhancement: a descriptive study. Complementary and Alternative Medicine, 10(11), 1-7.

Engin R, Pasinlioğlu T (2002). Erzurum ve Yöresinde İnfertil Kadınların İnfertilite İle İlgili Geleneksel İnanç ve Uygulamaları. Atatürk Üniversitesi Hemşirelik Yüksekokulu Dergisi, 5(1), 1-10.
Galhardo A, Cunha M, Pinto-Gouveia J, (2013). Mindfulness-Based Program for Infertility: efficacy study, Fertility and Sterility, 100(4), 1059-1068.

Ghazeeri GS, Awwad JT, Alameddine M et all. (2012). Prevalence and determinants of complementaryand alternative medicine use among infertile patients in Lebanon: a cross sectional study. BMC Complementary and Alternative Medicine, 12,129.

Jasani S, Heller B, Jasulaitis S, Davidson M, Cytron JH.(2016). Impact of astructured yoga program on anxiety in infertility patients: a feasibility study. Journal of Fertilization: In Vitro - IVF-Worldwide, Reproductive Medicine, Genetics \& Stem Cell Biology, 4,1-6. Kebapcilar AG, Kulaksizoglu M, Kebapcilar L, Gonen M. S, Unlü A, Topcu A, Demirci F, Taner C.E, (2013). Is there a link between premature ovarian failure and serum concentrations of vitamin $\mathrm{D}$, zinc, and copper? Menopause: The Journal of The North American Menopause Society, 20(1), 94-99.

Kirca N, Pasinlioglu T. (2019). The effect of yoga on stress level in infertile women. Perspectives in Psychiatric Care, 55(2), 319-327.

Kurçer MA, Eğri M, Genç M, Pehlivan E, Güneș G, Araoğlu L, Kaya M. (1999) İnfertil kadınların geleneksel halk kısırlık tedavileri konusundaki davranışları ve etkileyen faktörler, Turgut Özal Tıp Merkezi Dergisi, 6(4), 229332.

Levitas E, Parme, A, Lunenfeld E, Bentov Y, Burstein E, Friger M. (2006). Impact of hypnosis during embryo transfer on the out come of in vitrofertilization- embryo transfer: a case-control study. Fertility and Sterility, 85(5), 1404-1408.

Nalavade D, Shekar A, Shah, K. (2016). Effect of diet and nutrient intake on women who have problems of fertility. International Journal of Pure Applied Bioscience, 4(4), 198-204.

Oron G, Allnutt E, Lackman T, Sokal-Arnon T, Holzer H, Takefman J. (2015). Aprospective study using Hatha Yoga for stress reduction amongwomen waiting for IVF treatment. Reproductive BioMedicine Online, 30, 542-548.

Özcan H, Beji NK. (2016). İnfertilitede Tamamlayic1 ve Alternatif T1p Uygulamaları. Okmeydanı Tip Dergisi, 32(1), 36-44. 
Özkan SF, Karaca A, Sarak K. (2018). Complementary and Alternative Medicine Used by Infertile Women in Turkey. African Journal of Reproductive Health, 22 (2),40-49.

Sezer Ö. (2015). Türkiye'de Yeni Parlayan Bir İntegratif Tıp Yöntemi: Homeopati, Eurasian Journal of Family Medicine, 4(1), 1-6

Sezgin H, Hocaoğlu Ç. (2014). İnfertilitenin Psikiyatrik Yönü. Current Approaches in Psychiatry, 6(2), 165-184.

Sis Çelik A, Kırca N. (2018).İnfertil Kadınların Uyguladıkları Tamamlayıcı Ve Destekleyici Bakım Uygulamaları. Anadolu Hemşirelik ve Sağl1k Bilimleri Dergisi, 21(3), 178-188.

Stankiewicz M, Smith C, Alvino H, Norman R. (2007). The use of complementary medicine and therapies by pa- tients attending a reproductive medicine unit in So- uth Australia: A prospective survey. Australian and New Zealand Journal of Obstetrics and Gynaecology, 47(2), 145-9.
Taşkın L, 2012. Doğum ve Kadın Sağlı̆̆1 Hemşireliği. Sistem Ofset Matbaacılık. 11. Bask1, s. 547.

TC. Sağlık Bakanlığı Geleneksel ve Tamamlayıcı Tıp Uygulamaları Daire Başkanlığı, Geleneksel ve Tamamlayıc1 Tip Nedir? http:/getatportal.saglik.gov.tr. Güncelleme Tarihi: 12/06/2017, Erişim tarihi:06,05,2018.

Weiss AD, Harris CR, Smith JF. (2011). The use of complementary and alternative fertility treatments.Current Opinion in Obstetrics and Gynecology, 23, 195-199.

http://www.tdk.gov.tr/index.php?option=com yanli s\&view=yanlis\&kelimez $=18$, Erişim tarihi 20.05 .2018

Valoriani V, Lotti F, Vanni C, Noci C, Fontanarosa $\mathrm{N}$, Ferrari $\mathrm{G}$ et al.(2014). Hatha-yoga as a psychologicaladjuvant for women undergoing IVF: a pilot study. European Journal of Obstetetrics \& Gynecology and Reproductive Biology, 176, 158-162.

Yıldız S, Ürper S. (2013). İyileştirme sanatı: Homeopati. Integratif Tip Dergisi, 1(1), 32-36. 